\title{
Proposed Procedure to Improve Performance of an Artificial Pancreas and Pancreas Transplant: Review
}

\author{
Ali Algaddafi ${ }^{1 *}$ and Abdalmawla $\mathrm{Ali}^{2}$ \\ ${ }^{1}$ Department of Electrical and Electronic Engineering, Sirte University, Sirte-Libya \\ ${ }^{2}$ Depertement of Orthodontics, Sirte University, Sirte-Libya
}

"Correspondence author: Ali Algaddafi, Department of Electrical and Electronic Engineering, Sirte University, Sirte-Libya, libyan arab Jamahiriya, Tel: 7448295307; Fax: 7448295307; E-mail: alisirte@yahoo.com

Received date: March 07, 2017; Accepted date: March 15, 2017; Published date: March 20, 2017

Copyright: () 2017 Algaddafi A, et al. This is an open-access article distributed under the terms of the Creative Commons Attribution License, which permits unrestricted use, distribution, and reproduction in any medium, provided the original author and source are credited.

\begin{abstract}
Diabetes is a lifelong condition with no cure. Diabetes has a serious effect on the patient, especially pregnant women that may cause problems, whether overdose or low of the insulin in the blood stream. The patient must use insulin whether by pumping as in the artificial pancreas (closed loop) or by injecting insulin manual (opened loop). However, every method has its own advantages and disadvantages, e.g. the opened loop system for artificial pancreas may have a risk during the night when the patient sleep. On the other hand, the closed loop can administer insulin and glucose at the right time with the right amount. However, the artificial pancreas is not available yet and it required more improvement to be reliable. The algorithm of artificial pancreas consists of measuring glucose in the blood of a patient by using glucose sensor and sends a signal to an insulin pump to adjust basal insulin rated according to the desired amount of insulin that the patient need. This procedure required devices with the patient; however, some patient may be advised to have a pancreas transplant.
\end{abstract}

This paper reviews the current publication of an artificial pancreas and proposed a method to improve the control of an artificial pancreas. History of diabetes is described in this paper with a critical review of current studies. Also, it has tested pre-diabetes for pregnant women. The obtain results show that in breakfast the sugar level is increased high with random changing, hence based on the test, some foods should be ignored in breakfast, while other food recommended.

Keywords: Pancreas transplant; An artificial pancreas; Hyperglycemia; Diabetes; Closed-loop control system

\section{Introduction}

The history of diabetes disease starting since 1934, the diabetes was found by wells and Lawrence [1] while the first research grant in the UK was made in 1936 [2]. The first a counseling line that's available for 24 hours a day for patients was established in 1993 [3]. The insulin was discovered in 1921, while the continuous glucose monitoring was introduced in 1999. In recent, the artificial pancreas is still not a cure [4].

Overdosing the insulin may cause a low blood glucose, which has an immediate impact and complications such as seizures or death. On the other hand, Low insulin may cause high blood glucose (hyperglycemia), which has long-term complications, for example, nerve disease blindness, or kidney disease [5]. According to [6], the glucose concentration is less than $3.0 \mathrm{mmol} / \mathrm{L}(<54 \mathrm{mg} / \mathrm{dl})$, which is considered that increase the risk of severe hypoglycemia. Therefore, an artificial pancreas needs to be tighter blood glucose control in order to provide ease with the life for people who have diabetes and reduce the risk of diabetes complications (Figures 1 and 2). However, the tight blood sugar control remains a challenge, although some researchers were implemented some approaches. The one challenge could be the long insulin action time for a continuous subcutaneous infusion of insulin pumps, which may lead to reducing the performance of an artificial pancreas. Furthermore, it is expected that the people with diabetes by 2030 will increase to 150 million, wherein 2010 was around 280 million people $[7,8]$.

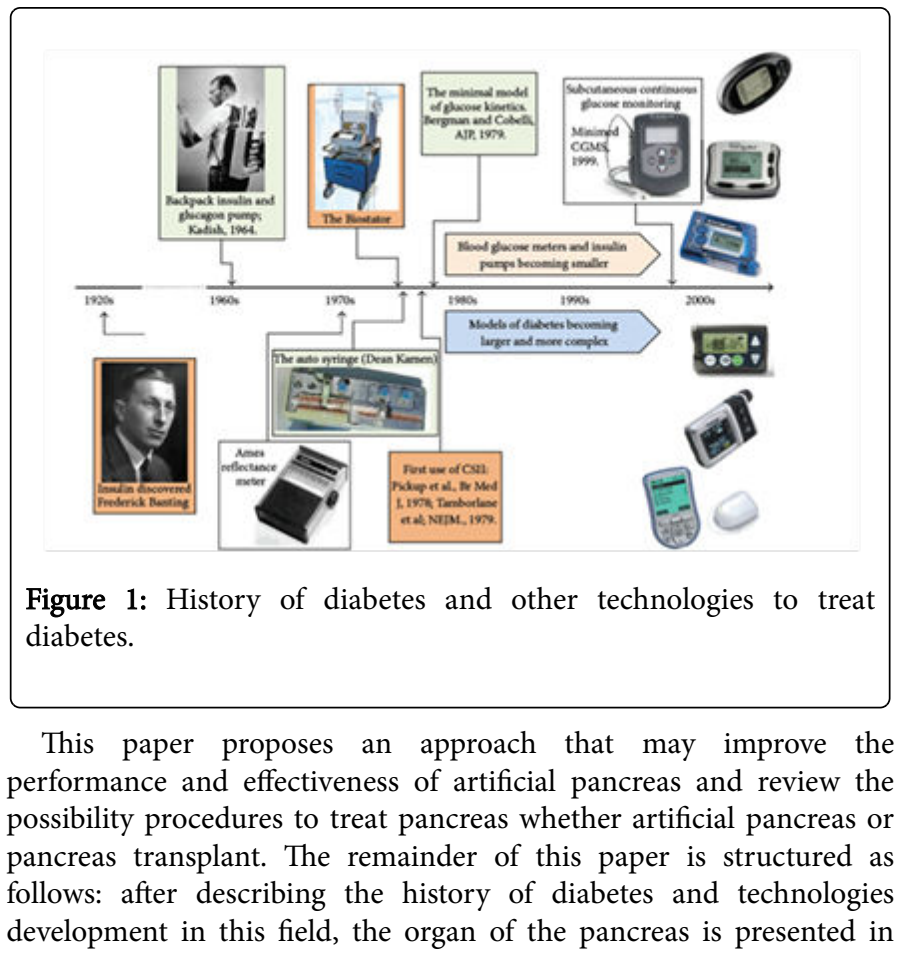


section II. Section III presents the methodology to treat diabetes where the artificial pancreas is discussed in detail with a new novel procedure to control artificial pancreas was proposed.

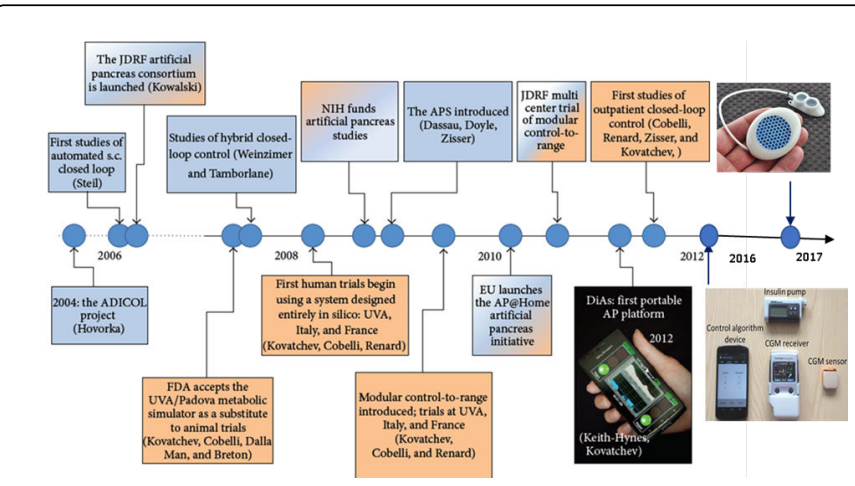

Figure 2: Timeline of developing the artificial pancreas in recent years.

Also, the pancreas transplant with a case study for pre-diabetes pregnant women was highlighted with the discussion. The final section draws the conclusion of this paper.

\section{An organ of pancreas}

The pancreas is a part in the human body that is responsible about the hormones insulin and glucagon. This is a complete system where it can control the number of the hormone insulin to maintain blood glucose targets between 4 and $7.8 \mathrm{mmol} / \mathrm{L}$ as shown in (Figure 3). The pancreas plays an essential role in converting the food that is eaten into fuel for the body's cells.

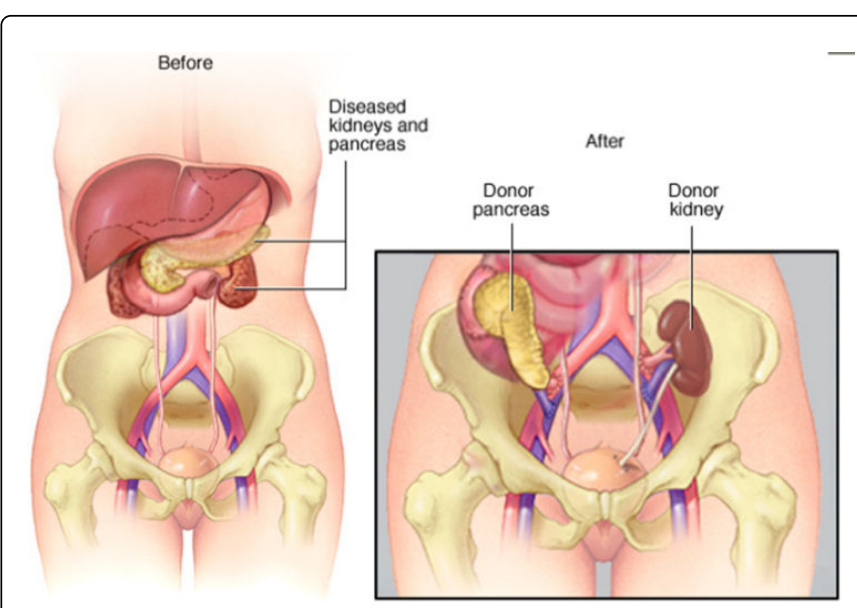

Figure 3: Pancreas transplants.

But, what are normal glucose/sugar numbers? The glucose numbers vary throughout the day. For someone without diabetes, which is called a non-diabetes person with a fasting blood sugar on awakening should be under $100 \mathrm{mg} / \mathrm{dl}$. However, before-meal the normal sugars are in the range between 70-99 mg/dl. "Postprandial" sugars may take onetwo hours after meals to be ready to measure where it should be less than $140 \mathrm{mg} / \mathrm{dl}[9]$.

\section{An example of recent funding project}

The diabetes disease has many complications such as heart disease, visionless, kidney disease, lower extremity amputations and death. Therefore, diabetes has developed the funding for research in diabetes since 1936 until in 2017, where the charity awarded $£ 58,500$ for a new $\mathrm{PhD}$ student grant [10]. The other project funded by the University of Leicester regarding diabetes. This project will involve analysing existing data sets to explore the relation between the local neighbourhood environment physical health, and mental health [11]. The first objective is the local neighbourhood environment where the variety of fast food is easily accessible; this fast food needs to be reduced and prevented it as it has a negative impact on the health of people.

The research question is that: Is the neighbourhood environment having significantly impacted on the behaviours and health of local people? This is a cap of research yet unclear and needs more investigations. This research may include modelling the future risk of adverse health results based on environment testing the effect of environment on the effectiveness of lifestyle interventions. Also, the different ethnic environment may have an influence on the health. Hence this is required to explore it during the period of study. Therefore, this project aims to develop a novel method to prevent and treat the metabolic disease in order to improve the health of the nation.

Based on the above idea, the authors think that varieties of food have a significant impact on the diabetes disease. Therefore, two or more countries were compared with the percentages of people who have diabetes in this section. In general, the diabetes is a disease that appears when the pancreas is dysfunction, where the hormone insulin cannot be injected into the blood of the body.

According to New Hampshire, Department of Health and Human Services the $9.2 \%$ of adults reported having diabetes. 6.8 of adults in New Hampshire in the US having diabetes [12], while in the UK the Birmingham has the highest diabetes rate show $9.3 \%$ of people having a risk of diabetes according to Varma [13]. In general, in the UK 6\% of the adult having diabetes [14]. In Arab countries and North Africa such as Morocco, Algeria, Tunisia, Libya, Egypt and further so on, were found diabetes between $10-20 \%$ in 2013 . However, diabetes in a rural area is less than the urban area. This is a good sign to validate the proposed study by the University of Leicester [11]. It can notice that the percentage of diabetes in the UK and the US almost the same due to the same food may be taken. However, in rural areas in Arab countries, the diabetes is less than the urban areas. This may be due to reduce the fast junk food.

\section{Type of diabetes disease}

It is important to know the type of diabetes to obtain the right treatment and avoid medical misdiagnosis. The diabetes disease may occur due to inheriting from a parent who has a gene mutation. Although there are many types of diabetes, but there are two common types that are type 1 and type 2 . Type 1 refers to a total lack of insulin, while type 2 refers to a little insulin but it cannot be affected. Type 1 is called Juvenile -onset or insulin-dependent diabetes where the immune system destroys the cells that produce the insulin. It cannot be prevented. Type 2 is called adult-onset or non-insulin dependent diabetes, or insulin resistance and it can be prevented. Also, there is another type of diabetes that occurs during pregnancy that is called gestation diabetes. Maturity-Onset Diabetes of the Young (MODY) is 
another type of diabetes along with LADA diabetes as shown in (Figure 4).

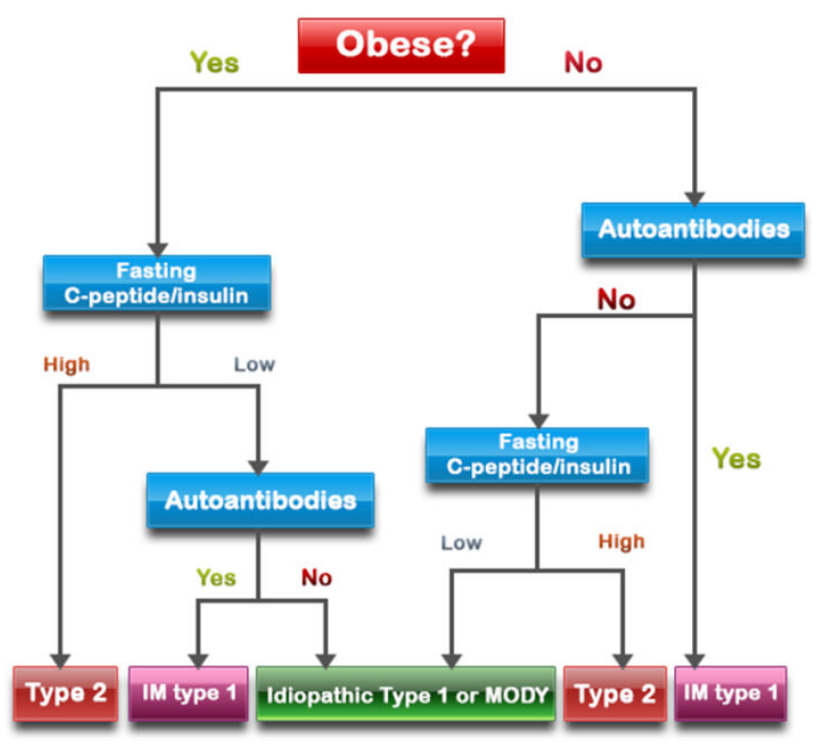

\section{Methodology}

Two methods could be used to treat diabetes beside the conventional/ classical approach. The conventional approach is based on injecting insulin or by using tables according to time and hours in the day. Although this approach is simple and convenient for people, it does not control the amount of insulin. Beside this it has some drawbacks such as people may forget the time of taking the medicine. It has annoyed people where the inject is inconvenient. It may have some contamination. It is also wasting the time of people. People inject insulin without measuring the glucose, which may have a negative effect as described in the introduction section of this paper. Also, in some countries, such as in developing countries, where the people are unable to know the level of sugar in the blood. Hence, they took insulin random. As the authors are an engineer, they would produce an idea for society and contribute to solving the international disease.

Firstly, the conventional method of injecting insulin that uncontrolled approach (open loop). The uncontrolled approach is approved that is not a reliable method due to limitation above. Therefore, the two approaches could be used. One is planted the pancreas, while another way is a pancreas transplant. The pancreas transplant is a complex method, which based on the operation procedure and it is required more investigations and experimentations on alternative animals before the human. The second approach is using an artificial Pancreas as below.

\section{An artificial pancreas}

Firstly, the history of an artificial pancreas is described in brief. In 1974, Albisser, et al. [15] developed the artificial pancreas, but it is only utilised for in clinical studies that time. According to Boiroux, et al. [16] the time constant is related to glucose transport from blood to subcutaneous tissues was $15 \mathrm{~min}$, where the parameters for the CGM model is given by Breton and Kovatchev [17]. However, this may not be accurate because the body of human still yet knows what time will respond for allowing the pancreas to give insulin.
The second approach is using the engineering control system as shown in Figure 5 to measure glucose in the blood stream of a patient and compared with the desired level of glucose in the blood, which should be in the range between 4-7.8 $\mathrm{mmol} / \mathrm{L}$, which is the blood level target. The error or difference should pass through some control such as a PID controller with a time delay to produce a control signal to allow inject the specific value of insulin in the body of the patient as shown in Figure 2. The method has advantages of maintaining the level of glucose to be between the $4-7.8 \mathrm{mmol} / \mathrm{L}$. This approach also is called an artificial pancreas.

Recently, the model predictive control was implemented by Boiroux et al. [16] to stabilise the blood glucose in patients overnight. Low blood glucose (hypoglycemia) may be caused by an overdose of an insulin that injects into the blood of a patient, which has a serious effect such as seizures, coma, or death [18]. Therefore, the dosage of insulin must be taken into account to be an as normal person and to allow the body of the patient to maintain the level of blood glucose target to be between $4-7.8 \mathrm{mmol} / \mathrm{L}$.

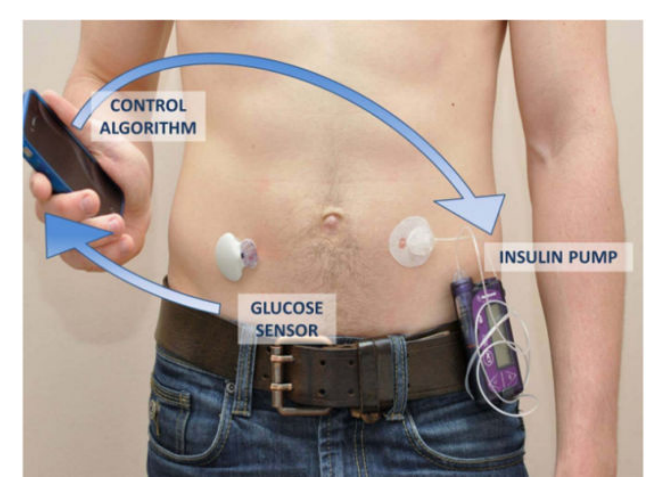

Figure 5: Portable artificial pancreas.

Continuous subcontinent insulin infusion injects into the patient blood to mitigate the endogenous glucose production. The Glucose Monitoring Devices (CGMs) is used to measure and monitor glucose in the blood. Once the patient takes a meal, the amount of insulin is administered to compensate the impact of carbohydrate intake [19].

The insulin action time and the insulin sensitivity factor are associated with the response of blood glucose to an insulin bolus [5] However, one drawback that many assumptions are considered, where these parameters of insulin action time are empirically determined by the patient which also may vary from day to day. The study of Boiroux et al revealed that the model predictive controller based on the adaptive ARMAX model gave better performance than the model predictive controller based on an ARMAX model and the ARIMAX model. However, the more weakness that the functions of the pancreas do not mention, where one function is producing the insulin to control the glucose level in the blood, while the other function does not take into account, which is the enzymes for digesting proteins and fat.

\section{Modelling an artificial pancreas}

Controlling blood glucose concentration for a patient with type 1 diabetes is still challenging, but the artificial pancreas offers a solution so far. There are many challenges for the artificial pancreas, such as variability over time with meals, time -varying delays on the measurement of glucose in blood and insulin infusion and noisy or 
interface of communication between elements of pancreas artificial that include insulin pump that has a specific approach to control and CGMs. The main aim is developing an artificial pancreas that has a low cost to be suitable for patients with type 1diabetes and artificial pancreas should be reliable with small size. There are many control techniques have been utilised for the artificial pancreas, such as PID control [20-25], adaptive control [26,27], model-predictive control [28], fuzzy logic control $[29,30]$ and linear -quadratic Gaussian $[25,31]$.

The artificial pancreas is presented by s-function in this paper so far. The code of the transfer function for diabetes is not recommended in practice. Also, the snack is used in this model with delay block to represent the time of patient are sleeping, which is considered eight hours' ant it may vary. The meals during the day are considered to be three meals at the specific time in the day such as breakfast, lunch and dinner to be at 7:00-7:36, 13:00-13:36, and 19:00-19:36 respectively. These all assumptions may not correctly; hence it is recommended to use this model on the animals before it is used for human. The results of this model are displayed as shown in (Figure 6).

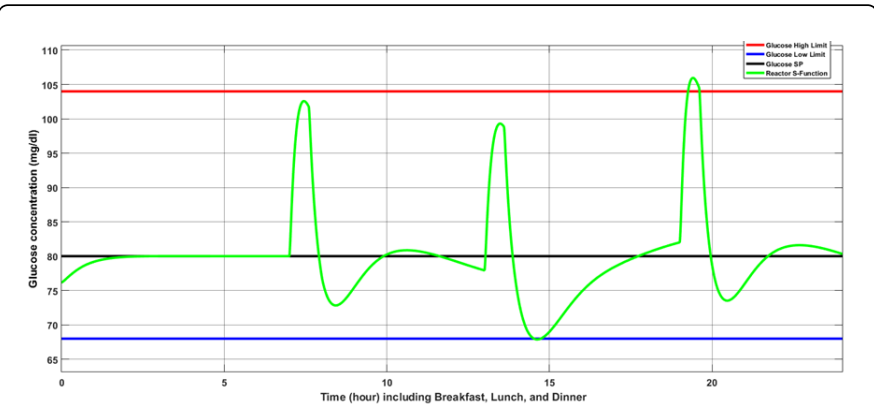

Figure 6: Acquired results of modelling artificial pancreas.

However, the proposed model below will help and facilitates finding the actual Transfer Function for a non-diabetes person, which will have a novel contribution in this field. Hence, it is easy to design control and designing perfect artificial pancreas that can satisfy the all requirements for a real pancreas as in the next section.

\section{Proposed procedure to improve an artificial pancreas}

Although Boirous et al. [16] demonstrated the response impulse for the non-linear Hovorka model, the response time is 4 hours which is too much. Also, the transfer function is built based on many assumptions. Therefore, since we have a glucose monitoring device signal or CGM as shown in Figure 7 and the output signal of glucose in $(\mathrm{mmol} / \mathrm{L})$ as shown in Figure 8 . The transfer function can be determined by the system identification in the MATLAB after importing these signals into identifying the Graphical User Interface (GUI) in the MATLAB workspace. Also, the design control for this transfer function will be easy and accurate. But these signals need to be taken from a normal person who does not have diabetes.

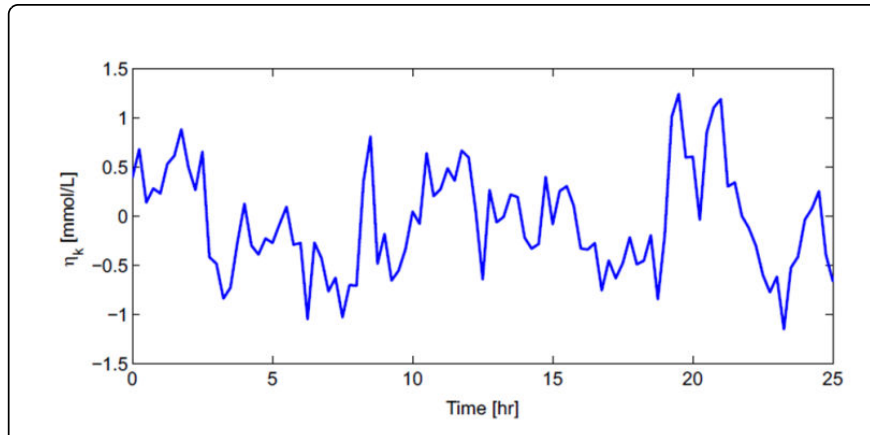

Figure 7: Continuous glucose monitoring devices realisation.
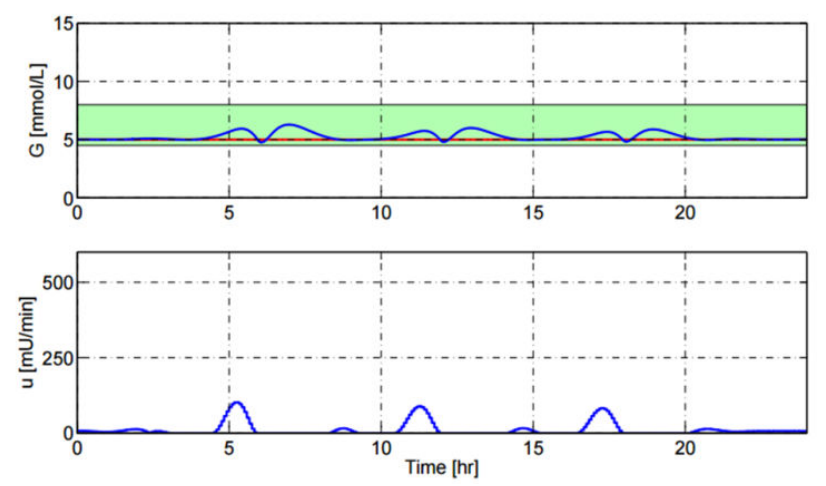

Figure 8: Insulin administration for the case with meal announcement in advance of the meal.

The profile of glucose for a non-diabetic person as presented in [32]. However, so far, the profile of glucose in non-diabetic person is still unknown, hence this is required more incorporation from other people at the hospital or other intuitions to adapt my idea. This will be a part of future work.

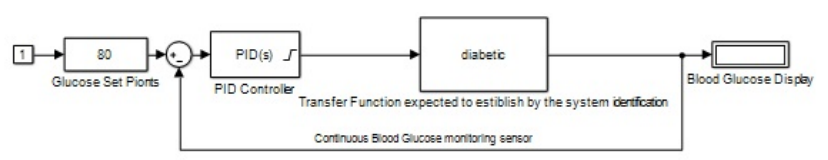

Figure 9: The proposed a way to perfect design of artificial pancreas after finding the transfer function.

Figure 9 shows the proposed model after finding the transfer function from the graphical user interface for system identification in MATLAB as shown in Figure 10 and are replaced instead of diabetic block. However, in order to make the measurement of a non-diabetes person, it requires Ethics approval of research, which will be part of future work. 
Page 5 of 7

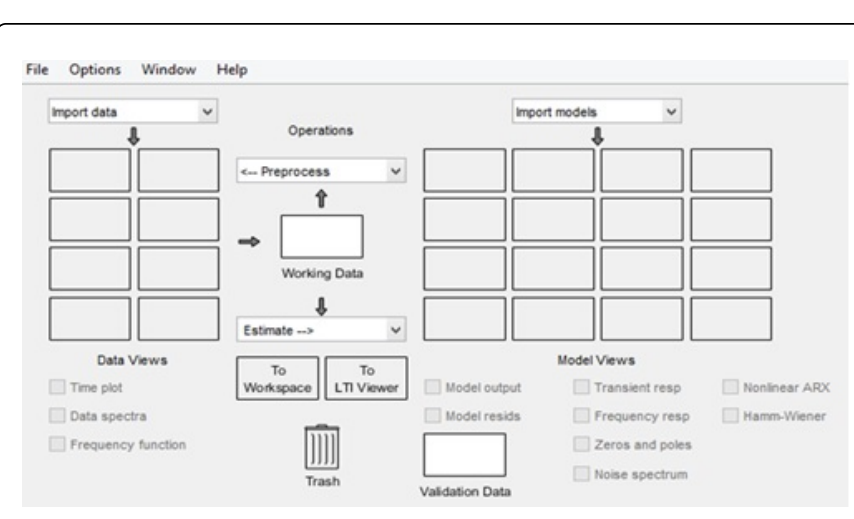

Figure 10: The graphical user interface that proposed to finding the transfer function of non-diabetes person.

\section{Pancreas transplant}

The aim of this work is to produce insulin again. Before a Pancreas transplant is described, it is important to highlight that the pancreas is an organ in the abdomen used to produce hormones and digestive juices. A pancreas transplant is an operation to replace a healthy pancreas from a donor or who recently died instead of the pancreas that dysfunction or add new healthy pancreas and leave the old pancreas because it may give some functions. Thus, the old damaged pancreas will be left in place to produce important digestive juices. In fact, a pancreas transplant is a complex and risky operation. Therefore, the pancreas transplant is required to assess carefully the patient to determine whether a pancreas transplant is required to assess carefully the patient whether a pancreas transplant is suitable and cold give benefit for the patient. This required to test blood pressure, and heart rate, urine, cardiac catheterization, and coronary angiography.

According to [33] in the UK, there are around a million people who have diabetes 1 , while a 200 people who has a Pancreas transplant each year.

The insulin is released automatically in the non-diabetes person to dispose of all the carbohydrate or sugar that accumulated during a meal. In normal person or non-diabetes person, the blood glucose range is between $60-100 \mathrm{mg} / \mathrm{dL}$ and $140 \mathrm{mg} / \mathrm{dL}$ or less after meals in the US system, while in the UK is between $4-7.8 \mathrm{mmol} / \mathrm{L}$. This will be explained in detail as in section below.

\section{Difference between $\mathrm{mmol} / \mathrm{L}$ and $\mathrm{mg} / \mathrm{dL}$ (factor ratio)}

The $\mathrm{mmol} / \mathrm{L}$ and $\mathrm{mg} / \mathrm{dL}$ are units used to measure the blood glucose level. The former is used in the UK, while the former is used in the US, North Africa where is located my country Libya, and continental Europe. The $\mathrm{mmol} / \mathrm{L}$ is millimoles per litre while the $\mathrm{mg} / \mathrm{dL}$ is milligrammes per 100 millitres. However, in some devices is used the $\mathrm{mmol} / \mathrm{L}$, while the other used the $\mathrm{mg} / \mathrm{dL}$, hence is important to know the Factor Ratio (FR) between the mmol/L and $\mathrm{mg} / \mathrm{dL}$. According to The Global Diabetes Community, the Factor Ratio (FR) between the $\mathrm{mmol} / \mathrm{L}$ and $\mathrm{mg} / \mathrm{dL}$ is a constant and its value is 18 . Therefore, we could imply the following format to convert from the $\mathrm{mmol} / \mathrm{L}$ to $\mathrm{mg} / \mathrm{dL}$ and vice versa:

\section{Case study of pregnant women with pre-diabetes}

\begin{tabular}{|c|c|c|c|c|}
\hline $\begin{array}{l}\text { No of } \\
\text { days }\end{array}$ & $\begin{array}{l}\text { Before } \\
\text { breakfas } \\
t\end{array}$ & $\begin{array}{l}\text { One hour after } \\
\text { breakfast }\end{array}$ & $\begin{array}{l}\text { One hour after } \\
\text { mid-day meal }\end{array}$ & $\begin{array}{l}\text { One hour after } \\
\text { mid-evening meal }\end{array}$ \\
\hline & 4.1 & 7.4 & 7.4 & 7 \\
\hline & 4.3 & 8.3 & 5.2 & 7.7 \\
\hline & 4.3 & 9.4 & 7.3 & 5.7 \\
\hline & 4.3 & 11.5 & 8.0 & 6.7 \\
\hline & 4.7 & 8.7 & 6.4 & 5.6 \\
\hline & 4.6 & 7.1 & 7.3 & 6.3 \\
\hline & 4.2 & 7.3 & 6.4 & 4.2 \\
\hline & 4.5 & 7.4 & 3.9 & 7.4 \\
\hline & 4.3 & 9.8 & 5.2 & 7.3 \\
\hline & 4.7 & 8.1 & 5.4 & 5.9 \\
\hline & 4.9 & 8.2 & 8.8 & 11.1 \\
\hline & 4.7 & 7.8 & 7.6 & 6.9 \\
\hline & 4.1 & 7.6 & 5.7 & 7.7 \\
\hline & 4.3 & 7.9 & 6.1 & 6.1 \\
\hline & 4.3 & 6.1 & 6.7 & 6.5 \\
\hline & 4.3 & 5.7 & 4.7 & 8.0 \\
\hline & 4.3 & 7.1 & 6.4 & 4.6 \\
\hline & 4.6 & 5.1 & 5.5 & 8.8 \\
\hline & 4.7 & 7.0 & 6.2 & 6.1 \\
\hline & 4.3 & 5.8 & 7.2 & 7.6 \\
\hline & 5.1 & 7.0 & 5.9 & 6.8 \\
\hline & 4.9 & 6.9 & 6.9 & 7.9 \\
\hline & 4.8 & 7.4 & 11.5 & 5.1 \\
\hline & 4.1 & 6.8 & 6.3 & 4.7 \\
\hline & 4.4 & 6.4 & 6.7 & 7.5 \\
\hline & 4.5 & 7.0 & 7.3 & 7.0 \\
\hline & 4.5 & 6.2 & 9.2 & 8.6 \\
\hline & 4.8 & 7.2 & 8.8 & 7.0 \\
\hline & 4.1 & 0.8 & 8.7 & 9.4 \\
\hline & 4.6 & 6.2 & 6.7 & 7.5 \\
\hline
\end{tabular}

Table 1: Blood test sugar level in pre-diabetes in pregnant women (gestation diabetes).

Diabetes in pregnant women may cause oversized babies, higher rates of birth defects, pre-term delivery and stillbirth than other pregnant women. Therefore, some researcher attempts to create an artificial pancreas, for example, some research at the University of Cambridge claimed that the first mother in the world who has diabetes 
to give the natural birth where the artificial pancreas was used [35] According to Stewart in University of Cambridge, treating diabetes in pregnant women could be challenging due to hormone levels are varied and blood glucose may be difficult to predict.

The methodology in this paper is taken based on the monitor Diary for pregnant women. This monitor diary helps to determine the balanced diet and help doctors or nurses to take a decision. The result of this test is shown in Figure 6. From this figure, we notice that even the low-fat food such as Cheese, yoghurt, corn flakes cause rise of blood glucose over the target level. However, Brown toast with eggs helps keep the Blood glucose at the target level.

Insulin is continuous releases in normal person into the blood stream with an automatic system where after 5-6 min the insulin is quickly destroyed, but the effect on cells may be taken 1-1/2 hours. The main problem with an artificial pancreas is that if the insulin release into the bloodstream, the artificial pancreas only stops inject insulin.

From Figure 11, we notice that the gestation diabetes is uncontrolled where it can increase after breakfast or lunch or dinner. Hence, the artificial pancreas could be a solution for this problem, where the weight of baby in pregnant women may increase to be above four kg. This lead the women to deliver baby by Caesarean.

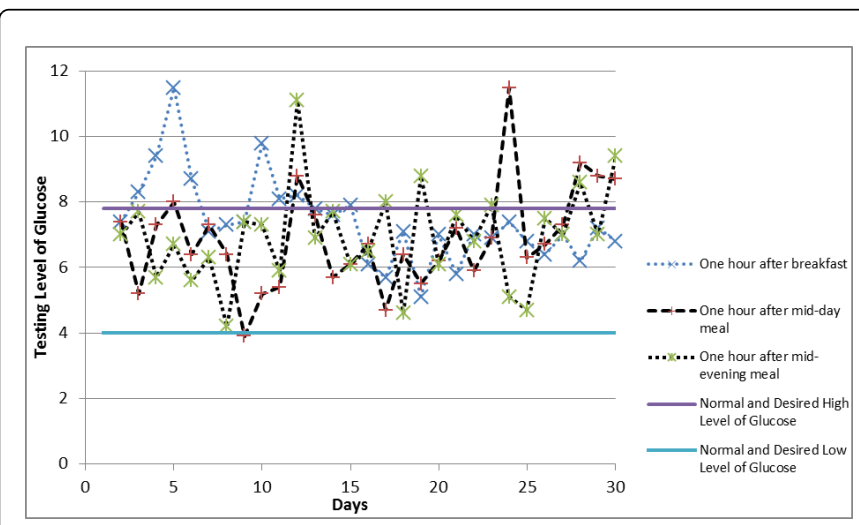

Figure 11: Gestation diabetes in pregnancy women, where the blue lines indicates the target level of glucose.

In this paper, we advise the pre-diabetes, women, to take Brown toast with eggs in breakfast while the other meals, the pregnant women can take an apple or the past, Also, we advise that the Rice and bread be ignored during the period of pregnancy. Some studies show that there are some plants are useful to keep pancreas health such as Gentiana Lutea, Equisetum Arvense which is called Horsetail, Calendula Officinalis, Tavaxacum Officinale and Origanum Vwlgare. Horsetail may help Pancreas to perform his functions if it is taken within first 5 weeks [36]. According to Top Natural Remedies in the Horsetail has been approved to be ant-diabetic and conducted a study on rats.

\section{Conclusion}

This paper presents a critical review for an artificial pancreas. It also presented a new proposed method that can easily find the transfer function from non-diabetic person where it is required to measure the insulin that produced by the pancreas in the body, then we find the transfer function. Based on this transfer function, we can find the optimal control for an artificial pancreas that consists of the glucose sensor and the control procedure such as internal control mode and insulin pump. Many techniques of control were utilized to regulate the blood glucose concentration in patients with type 1 diabetes. In my point of view that the control procedure such as internal control mode or PID controller is enough for this transfer function.

Pancreas transplant was critically reviewed and it can be implemented based on the decision of special surgery doctors and the availability of the pancreas that taken from a donor. Also, in this paper, we recommend that the pregnant women should tight blood glucose at an acceptable level. The pregnant women have challenges to maintain blood glucose levels within a safe level, particularly at night time. When the blood glucose level is high, it may lead to cause a serious problem for a baby such as a die, a major deformity. While low blood glucose which is called Hypogyny, camera may lead to maternal mortality. The case study for pre-diabetes pregnant women studied, with this approach, we manage to control the blood glucose level to be at target level between $4.0-7.8 \mathrm{mmol} / \mathrm{L}$. While, the artificial pancreas control is improved nowadays in practice, but it is still imperfect if it is compared with the non-diabetes person. Hence, the regulation or control of blood glucose via artificial pancreas is required more investigations.

\section{Acknowledgements}

I would like to introduce something for society in general and practically to my nephew Mubarak who suffer from diabetes.

\section{References}

1. Diabete UK (2015) history of diabetes. Journal of Diabetes and Complications 19: 12-16

2. Fox RC (2011) In the Field: A Sociologist's Journey: Transaction Publishers. Endocrinol Soci 20: 21-36.

3. Frowen P, O'Donnell M, Burrow JG, Lorimer DL (2010) Neale's Disorders of the Foot: Elsevier Health Sciences. UK J Diabet 10: 15-18.

4. Kovatchev BP (2012) Diabetes technology: markers, monitoring, assessment, and control of blood glucose fluctuations in diabetes. Scientifica 11: 17-22.

5. Boiroux D, Jorgensen JB, Poulsen NK, Madsen H (2012) Model predictive control algorithms for pen and pump insulin administration. Technical University of Denmark 15: 18-22.

6. IHS Group (2002) Glucose concentrations of less than $30 \mathrm{mmol} / \mathrm{L}(54$ $\mathrm{mg} / \mathrm{dL}$ ) should be reported in clinical trials: a joint position statement of the American Diabetes Association and the European Association for the Study of Diabetes. Diabetes Care 40: 155-157.

7. Shaw JE, Sicree RA, Zimmet PZ (2010) Global estimates of the prevalence of diabetes for 2010 and 2030. Diabetes Clin Pract 87: 4-14.

8. Mayo Clinic Staff (2016) Pancreas transplant. Mayo Clinic 15: 263.

9. David Sperol (2016) What Is a Normal Blood Sugar Level. Glucose Conversion 2: 15-22.

10. Association of Medical Research Charities (2015) Medical Research Charities. PhD Studentship 02: 19-22.

11. Bodicoat D, Khunti M (2017) The impact of local neighborhood environment on lifestyle behaviors and health outcomes. Med Health Sci $17: 22$.

12. New Hampshire (2013) Diabetes. Insulin Sensitivity $02: 18-23$.

13. Anuji Varma (2013) Birmingham has highest diabetes rate in the UK. Diabetes Rate 22: 18-41.

14. Gatineau Mary, Hancock Caroline, Holman Naomi, Outhwaite Helen, Oldridge Lorraine, et al. (2014) Adult obesity and type 2 diabetes. Public Health England 15: 18-20. 
Citation: Algaddafi A, Ali A (2017) Proposed Procedure to Improve Performance of an Artificial Pancreas and Pancreas Transplant: Review. J

15. Albisser A, Leibel B, Ewart T, Davidovac Z, Botz C, et al. (1974) An artificial endocrine pancreas. Diabetes 23: 389-396.

16. Boiroux D, Duun-Henriksen AK, Schmidt S, Nørgaard K, Poulsen NK, et al. (2001) Adaptive control in an artificial pancreas for people with type 1 diabetes. Control Eng Practice 58: 332-342.

17. Breton M, Kovatchev B (2008) Analysis, modelling, and simulation of the accuracy of continuous glucose sensors. J Diab Sci Technol 2: 853-862.

18. American Diabetes Association (2017) An artificial endocrine pancreas. Diabetes 23: 89-99.

19. Technical University of Denmark (2017) The Artificial Pancreas Diabetes \& Control. Scientific Computing. DTU Computer 5: 123.

20. Bequette BW (2005) A critical assessment of algorithms and challenges in the development of a closed-loop artificial pancreas. Diabetes Technol Therapeut 7: 28-47.

21. Steil GM, Rebrin K, Darwin C, Hariri F, Saad MF (2006) Feasibility of automating insulin delivery for the treatment of type 1 diabetes. Diabetes 55: 3344-3350.

22. Renard E, Place J, Cantwell M, Chevassus H, Palerm CC (2010) closedloop insulin delivery using a subcutaneous glucose sensor and intraperitoneal insulin delivery feasibility study testing a new model for the artificial pancreas. Diabetes Care 33: 121-127.

23. Steil GM, Palerm CC, Kurtz N, Voskanyan G, Roy A, et al. (2011) the effect of insulin feedback on closed loop glucose control. The J of Clinical Endocrinology and Metab 96: 1402-1408.

24. Ruiz S, Sherr JL, Cengiz E, Carria L, Roy A, Voskanyan G, et al. (2012) Effect of insulin feedback on closed-loop glucose control: a crossover study,. J Diab Sci Technol 6: 1123-1130.

25. Turksoy K, Cinar A (2014) Adaptive control of artificial pancreas systems-a review. Journal Health Care Eng 5: 1-22.
26. El-Khatib FH, Russell SJ, Nathan DM, Sutherlin RG, Damiano ER, et al (2010) A bihormonal closed-loop artificial pancreas for type 1 diabetes. Sci and Trans Med 27: 23-27.

27. Turksoy K, Bayrak ES, Quinn L, Littlejohn E, Cinar A (2013) Multivariable adaptive closed-loop control of an artificial pancreas without meal and activity announcement. Diabetes Technol Therapeut 15: 386-400.

28. Cobelli C, Renard E, Kovatchev B (2010) Artificial pancreas: past, present future. Diabetes 60: 2672-2682.

29. Atlas E, Nimri R, Miller S, Grunberg EA, Phillip M (2010) Md-logic artificial pancreas system. Diabetes Care 33: 1072-1076.

30. Nimri R, Atlas E, Ajzensztejn M, Miller S, Oron T, et al. (2012) Feasibility study of automated overnight closed-loop glucose control under MDlogic artificial pancreas in patients with type 1 diabetes: the DREAM Project. Diabetes Technol Therapeut 14: 728-735.

31. Patek SD, Breton MD, Chen Y, Solomon C, Kovatchev B et al. (2007) Linear quadratic gaussian-based closed-loop control of type 1 diabetes. J Diab Sci Technol 1: 834-841.

32. Freckmann G, Hagenlocher S, Baumstark A, Jendrike N, Gillen RC, et al, (2007) Continuous glucose profiles in healthy subjects under everyday life conditions and after different meals. J Diab Sci Technol 1: 695-703.

33. NHS (2016) Who can have a pancreas transplant. Gastroenterology 92: 203-209.

34. The Global Diabetes Community (2017) Consideration of blood glucose level. Blood Sugar Converter 14: 156.

35. University of Cambridge (2015) World first for artificial pancreas team. J Pancreatic Disorders 22: 154-168.

36. Top Natural Remedies (2016) Keep your pancreas Healthy with these 5 plants. J Endocrinology 32: 162-181. 